\title{
PRIVATE CLOUD MENGGUNAKAN PROXMOX VE PADA SISTEM INFORMASI AKADEMIK POLITEKNIK PURBAYA
}

\author{
${ }^{1}$ Fitriana Fajrin, ${ }^{2}$ Ahmad Sabiq \\ ${ }^{1}$ Program Studi Teknik Informatika Politeknik Purbaya, Tegal, Indonesia \\ ${ }^{2}$ Program Studi Teknik Informatika Universitas YARSI, Jakarta, Indonesia \\ E-mail: fitriana.f@purbaya.ac.id, ahmad.sabiq@yarsi.ac.id
}

\begin{abstract}
The development of information technology indirectly require changes to the computational needs. In achieving the expected computing needs, some emerging computing paradigm, referred to as Cloud Computing. Private Cloud is a cloud-computing services are provided to meet the internal needs of an organization / company. By using Proxmox OS as the main foundation, the server private cloud built on virtual technology that can provide the computing needs of Academic Information Systems at the Politeknik Purbaya. Besides virtual technology capable of providing support to the Private Cloud to produce the most effective alternative solutions for the development of an integrated system.
\end{abstract}

Keyword: Cloud Computing, Private Cloud, Virtual Server

\begin{abstract}
Abstrak
Perkembangan teknologi informasi secara tidak langsung memerlukan perubahan kebutuhan komputasi. Dalam mencapai kebutuhan komputasi yang diharapkan, ada beberapa paradigma komputasi yang muncul, salah satunya yaitu Cloud Computing atau komputasi awan. Private Cloud sendiri merupakan layanan cloud computing yang disediakan untuk memenuhi kebutuhan internal organisasi/perusahaan. Dengan menggunakan Proxmox OS sebagai landasan utama, server private cloud yang dibangun pada teknologi virtual dapat memberikan kebutuhan komputasi Sistem Informasi Akademik di Politeknik Purbaya. Selain itu, teknologi virtualisasi mampu memberikan dukungan kepada Private Cloud untuk menghasilkan solusi alternatif yang efektif untuk pengembangan sistem yang terintegrasi.
\end{abstract}

Kata kunci: Cloud Computing, Private Cloud, Virtual Server

\section{Pendahuluan}

Perkembangan teknologi informasi secara tidak langsung menuntut adanya perubahan terhadap kebutuhan komputasional, mulai dari sumber daya, media penyimpanan maupun aspek kecepatannya. Oleh karena itu, peningkatan layanan komputasi ini dianggap penting untuk memenuhi kebutuhan masyarakat dalam mengakses informasi secara up to date.

Dalam mencapai tingkat komputasi yang diharapkan, beberapa paradigma komputasi mulai bermunculan, salah satunya yaitu komputasi awan atau yang sering dikenal dengan istilah cloud computing (Bary \& Dick 2013). Dengan beberapa keunggulan yang dimiliki, banyak perusahaan besar telah mengimplementasikan dan mengembangkan teknologi cloud computing, seperti Amazon, Google, IBM, Dell, Microsoft dan Sun (Jadeja \& Modi 2012).

Saat ini terdapat tiga jenis layanan cloud computing yang umumnya digunakan pada suatu organisasi atau perusahaan, yaitu Public Cloud, Private Cloud dan Hybrid Cloud. Pada public cloud, layanan cloud disediakan untuk umum atau perusahaan, yang dimiliki oleh suatu perusahaan penyedia layanan dengan menjual layanan cloud. Pada private cloud infrastruktur cloud hanya disediakan untuk individu atau sebuah organisasi yang dikelola sendiri atau oleh pihak ketiga. Sedangkan Hybrid Cloud merupakan perpaduan dari public dan private cloud (Goyal 2014).

Pada penelitian ini, penulis mengimplementasikan server private cloud untuk kebutuhan Sistem Informasi Akademik (SIA) Politeknik Purbaya yang telah dikembangkan sebelumnya yang menjadi perangkat lunak berbasis web untuk pelaksanaan pengolahan data 
akademik di Politeknik Purbaya. Adanya teknologi ini diharapkan agar pelaksanaan pengolahan data akademik dapat berjalan efektif dan efisien. Sebelumnya, SIA yang telah dikembangkan belum dapat digunakan secara optimal, dikarenakan sistem belum mendapat dukungan teknologi komputasi yang memadahi. SIA yang berjalan di atas jaringan Local Area Network (LAN) diimplementasikan pada server konvensional dengan spesifikasi hardware minimum. Hal ini sering mengakibatkan lambatnya pemrosesan data ketika SIA digunakan oleh beberapa user secara bersamaan. Karena itu, dibutuhkan adanya inovasi agar penggunaan SIA dapat dioptimalkan sehingga pemanfaatan SIA berjalan maksimal, seperti inovasi penggunaan teknologi private cloud.

\subsection{Konsep Cloud Computing}

Cloud Computing adalah sebuah model yang memungkinkan sebuah komputasi dapat diakses dimanapun, memberikan kenyamanan, akses jaringan on-demand dalam berbagi sumber daya komputasi yang dapat dikonfigurasi (misalnya, jaringan, server, storage, aplikasi, dan layanan) (Mell \& Timothy 2011). Model komputasi cloud memiliki 5 karakteristik penting yaitu On-demand self-service, akses jaringan yang luas, resource pooling, rapid elasticity, dan measured service (Mell \& Timothy 2011).

Istilah cloud sendiri muncul sebagai metafora dari internet yang pada dasarnya merupakan jaringan yang menyediakan akses remote ke seperangkat sumber daya desentralisasi Teknologi Informasi (Erl \& Ricardo 2013).

\subsection{Private Cloud Computing}

Private Cloud Computing merupakan layanan cloud computing yang tersedia untuk memenuhi kebutuhan internal dari suatu organisasi/ perusahaan (Budiyanto, 2012).

Private Cloud memberikan keamanan dan privasi yang lebih dari awan publik, dan penghematan biaya dalam hal ini menggunakan kapasitas sebelumnya yang tidak terpakai dalam pusat data yang sudah ada. Kemampuan private cloud menyediakan layanan virtual dapat memaksimalkan penggunaan hardware, sehingga dapat mengurangi biaya dan kompleksitas (Goyal 2014).

\subsection{Teknologi Virtualisasi}

Virtualisasi merupakan sebuah teknologi yang memungkinkan pengguna membuat versi virtual dari sesuatu yang bersifat fisik, misalnya sistem operasi, storage data atau sumber daya jaringan (Utomo 2014). Proses tersebut dilakukan oleh sebuah perangkat lunak bernama Hypervisor (Utomo 2014).

\subsection{Hypervisor}

Hypervisor merupakan jenis software yang memungkinkan sebuah komputer dapat menjalankan lebih dari satu sistem operasi, melalui suatu proses yang disebut dengan virtualisasi, software ini membuat setiap sistem operasi berfikir bahwa menjalankan proses pada hardware yang sebenarnya (Agusti 2013). Hypervisor disebut juga sebagai Virtual Machine Manager (VMM). Hypervisor terletak diantara physical hardware dan sistem operasi, untuk kemudian menampilkan hardware virtual pada semua software yang berjalan. Pada hypervisor, setiap virtual machine terdiri dari sebuah sistem operasi guest, hypervisor dapat berjalan secara langsung pada hardware fisik (physical hardware), dalam hal ini dikenal sebagai jenis bare metal atau didalam host operating system disebut sebagai software hypervisor (Agusti 2013).

Hypervisor dapat dianalogikan sebagai sebuah wadah yang menjalankan dan mengatur virtual machine yang digunakan (Agusti 2013). Terdapat tiga tipe hypervisor, yaitu type 0, type 1 dan type 2. pada hypervisor type 0 merupakan hypervisor tipe lama yang tidak membutuhkan sistem operasi pada mesin host, VMM merupakan firmware yang sudah menjadi bawaan dari mesin host. Pada hypervisor type 1 terdapat sistem operasi yang berjalan khusus secara native sebagai VMM pada hardware mesin host, atau dapat juga sistem operasi yang umum namun menyediakan fungsi khusus sebagai VMM. Pada hypervisor type 2 keterlibatan sistem operasi sangat sedikit pada virtualisasi, VMM merupakan software yang dijalankan dan dikelola oleh mesin host. (Silberschatz \& Gagne 2012).

\subsection{Proxmox}

Proxmox VE (Virtual Environment) merupakan salah satu distro Linux berbasis Debian yang dikhususkan sebagai distro virtualisasi (Sugianto 2011). Proxmox secara default menyertakan OpenVZ dan Kernel-Based Virtual Machine (KVM) dan disediakan dalam mode teks (console mode) dimana proses administrasinya dilakukan dengan menggunakan antarmuka berbasis web (Sugianto 2011).

Proxmox disediakan hanya untuk mesin 64 bit sehingga tidak bisa digunakan untuk mesin 32 bit (Sugianto 2011). Selain itu, jika ingin menggunakan KVM, Proxmox membutuhkan 
motherboard/processor yang mendukung teknologi virtualisasi misalnya Intel VT/AMD-V (Sugianto 2011).

\subsection{Network Development Life Cycle (NDLC)}

Terdapat beberapa metode pengembangan dalam melakukan perancangan jaringan (Stiawan, 2009). Network Development Life Cycle (NDLC) merupakan salah satu metode yang digunakan dalam membangun sebuah jaringan. Seluruh proses dalam metode NDLC ditampilkan pada Gambar 1.

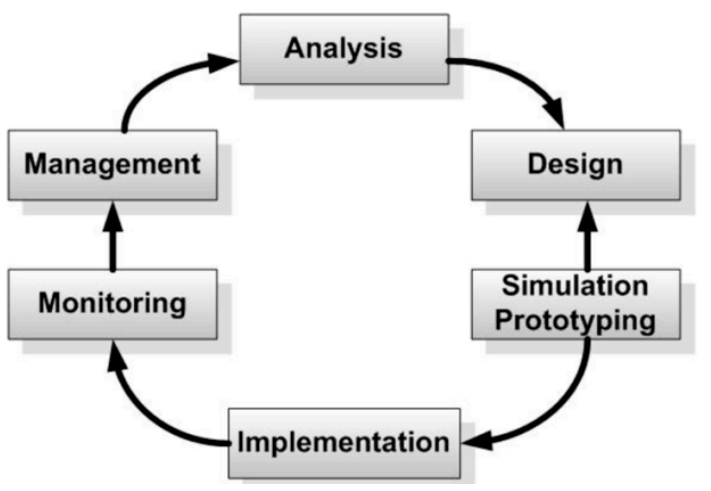

Gambar 1. Siklus Network Development life cycle (NDLC) (Goldman \& Rawles 2004)

\section{Metode penelitian}

Model proses Network Development Life Cycle (NDLC) selanjutnya digunakan penulis sebagai metode yang digunakan untuk menganalisis hingga merancang infrastruktur server private cloud.

\subsection{Analisis}

Proses analysis dilakukan penulis untuk mengetahui kebutuhan Politeknik Purbaya dalam membangun layanan Private Cloud. Selain itu, penulis menganalisis topologi jaringan yang sudah tersedia di Politeknik Purbaya. Tahapan ini melalui beberapa metode yang dilakukan penulis seperti studi pustaka tentang layanan cloud computing khususnya private cloud, wawancara, survey langsung ke lapangan, dan menelaah setiap data yang didapat dari data-data sebelumnya.

\subsection{Desain}

Setelah mengetahui kebutuhan Politeknik Purbaya terhadap layanan Private Cloud melalui proses analisis, penulis melakukan proses design. Pada tahap ini dibuatkan desain struktur topologi seperti yang ditunjukkan pada Gambar 2, sehingga gambaran atas kebutuhan yang ada dapat didefinisikan pada tahap selanjutnya.

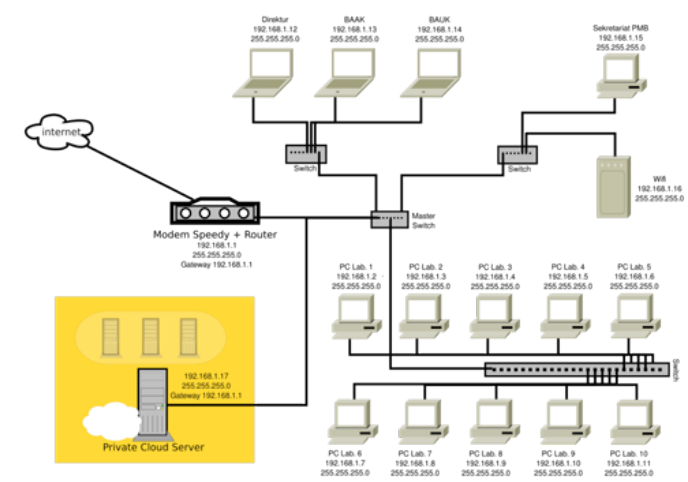

Gambar 2. Topologi Jaringan dengan Menambahkan Server Private Cloud

\subsection{Simulation Prototype}

Pada proses Simulation Prototype, penulis membuat desain topologi server Private Cloud dengan bantuan tool Dia.

\subsection{Implementasi}

Pada tahap Implementasi, penulis melakukan eksperimen dengan membangun layanan infrastruktur server Private Cloud yang mengacu pada desain yang telah dibuat sebelumnya.

Perangkat utama yang dibutuhkan pada eksperimen ini adalah dua buah komputer yang akan digunakan sebagai server dan sebagai klien, spesifikasi hardware yang digunakan untuk komputer server adalah sebagai berikut:

a) Processor : Intel Core2duo E8400

b) Memory :2Gb DDR2

c) Harddisk : Seagate 160Gb SATA

d) Lan Card : Broadcom ${ }^{\circledR}$ Integrated Gigabit Networking (BRCM 57780)

e) Lan Cable : UTP

f) Sistem Operasi : Proxmox VE 2.2

Sedangkan spesifikasi hardware yang digunakan pada klien yaitu:

a) Processor : AMD Dual Core E-300

b) Memory : 2 GB DDR3 PC-10600

c) Hard disk : 500 GB Serial

d) Lan Card : Realtek Semiconductor Co., Ltd. RTL8101E/RTL8102E

e) Lan Cable : UTP

f) Sistem Operasi : Xubuntu 14.04 LTS 32 bit

Beberapa software yang digunakan dalam implementasi sistem, antara lain:

a) Sistem operasi Ubuntu Server 14.04 LTS sebagai sistem operasi yang digunakan pada web server dan database server. 
b) Phpmyadmin, digunakan pada database server sebagai user interface dalam menampilkan mysql Graphical User Interface (GUI) berbasis web

c) Apache web server

d) MySQL server

e) Vsftpd yang merupakan aplikasi FTP dan berfungsi untuk menerima file yang dikirim melalui perangkat lain.

Tahap pertama yang dilakukan pada eksperimen ini adalah melakukan instalasi pada komputer server menggunakan sistem operasi Proxmox VE. Proxmox bertindak sebagai fondasi utama dalam membangun infrastruktur virtual server pada layanan Private Cloud.

Seluruh aktivitas konfigurasi Proxmox dilakukan melalui sisi klien, dimana klien mengakses server dengan web browser melalui port 8006 untuk dapat menampilkan antarmuka sistem operasi Proxmox seperti yang terlihat pada Gambar 3.

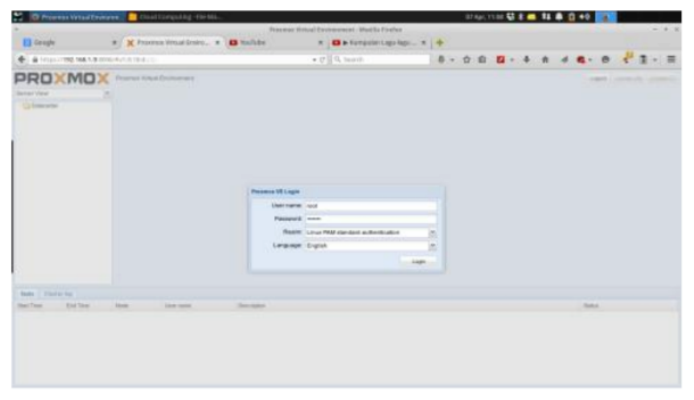

Gambar 3. Halaman Login Proxmox VE 3.4

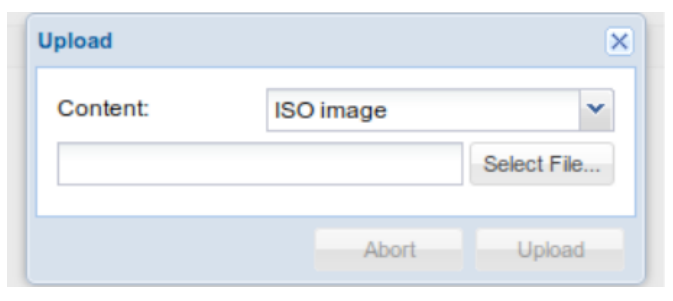

Gambar 4. Jendela upload File sistem operasi di Proxmox VE

Tahap berikutnya adalah melakukan upload ISO Ubuntu Server 14.04 yang akan digunakan sebagai sistem operasi dari sistem guest yang digunakan sebagai web server dan database server seperti yang ditunjukan pada Gambar 4. Setelah proses upload berhasil dilakukan, tahapan selanjutnya yaitu membuat Virtual Machine (VM) seperti yang ditunjukan pada Gambar 5. Penulis membuat dua buah VM yang akan digunakan secara aktif. Pertama yaitu membuat VM yang akan digunakan sebagai web server dan berikutnya yaitu membuat VM yang akan digunakan sebagai database server.

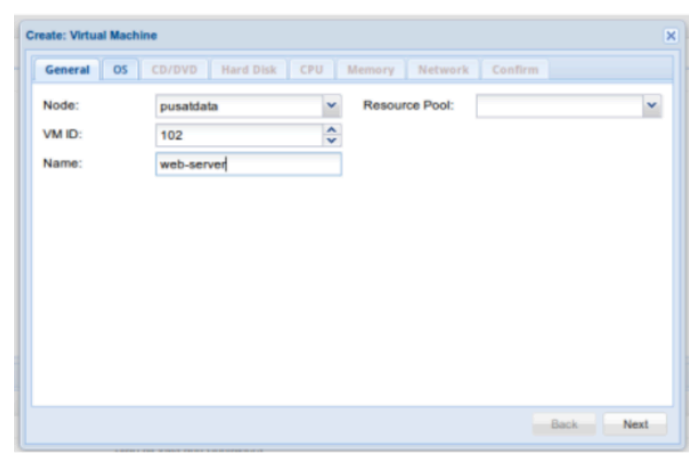

Gambar 5. Tampilan awal dalam membuat VM untuk web server

Langkah berikutnya yang dilakukan pada tahap implementasi adalah meng-install Sistem Informasi Akademik (SIA), terdapat beberapa langkah yang dilakukan oleh penulis untuk menginstall SIA, antara lain:

a) Meng-upload seluru file SIA ke dalam web server menggunakan FileZilla. Path lokasi untuk meletakkan seluruh file SIA yaitu pada /var/www/html.

b) Mengakses database server dan melakukan import database SIA untuk dimasukkan ke dalam database server.

c) Dari sisi web server, konfigurasi dilakukan pada file koneksi.php yang terletak pada/var/www/html/SIA/config agar web server dapat terkoneksi dengan database server.

\subsection{Monitoring}

Setelah tahap Implementasi berhasil dilakukan, penulis melanjutkan tahap monitoring. Pada tahap ini penulis melakukan pengamatan terhadap kinerja sistem yang telah dibangun dan jaringan.

\subsection{Management}

Dalam tahapan management, salah satu yang paling menjadi perhatian yaitu masalah policy (kebijakan). Kebijakan perlu dibuat untuk mengatur agar sistem yang telah dibangun dan berjalan dengan baik dapat berlangsung lama dan unsur reliability atau kehandalan dari sistem dapat terjaga.

\section{Hasil dan Pembahasan}

Dari percobaan yang sudah dilakukan, dilakukan pengujian untuk memeriksa apakah program SIA berhasil di-install dan dapat dijalankan melalui web browser dari sisi klien. 
Dari hasil pengujian, dengan mengakses laman http://192.168.1.18/SIA seperti pada Gambar 6, ditunjukkan bahwa sistem telah berhasil di-install.

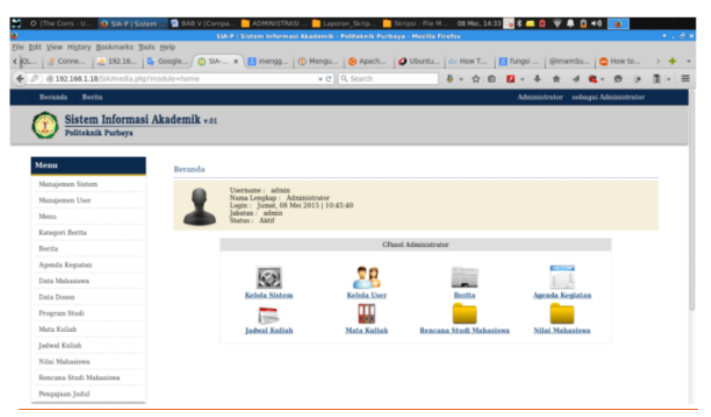

Gambar 6. Tampilan halaman beranda Sistem Informasi Akademik yang diakses melalui klien

Dari hasil penelitian yang telah dilakukan, didapatkan bahwa private cloud dapat diimplementasikan dengan menggunakan Proxmox VE sebagai fondasinya untuk kebutuhan Sistem Informasi Akademik di Politeknik Purbaya. Private Cloud yang telah dibangun mampu menyediakan antarmuka yang efisien untuk proses kegiatan pengelolaan data akademik yang dapat diakses menggunakan Local Area Network (LAN).

Eksperimen yang dilakukan setelah sistem berhasil di-install adalah dengan menguji kinerja dari sistem private cloud dan kinerja dari jaringan, pengujian dilakukan dengan mengukur utilisasi CPU dan pemakaian memori, serta menguji response time pada localhost dan sistem private cloud. Server localhost dan sistem private cloud yang diujikan sama-sama memanfaatkan satu komputer fisik.

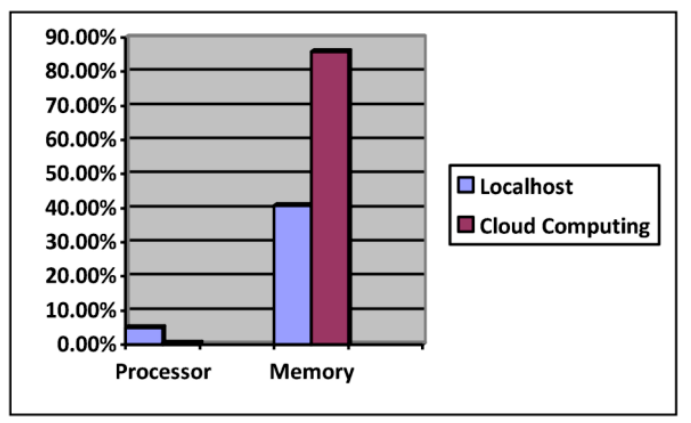

Gambar 7. Utilisasi CPU dan pemakaian memori pada server localhost dan sistem private cloud.

Dari pengukuran yang telah dilakukan, didapatkan hasil pengamatan utilisasi CPU dan pemakaian memori yang ditunjukkan pada Gambar 7. Dari hasil pengukuran tersebut dapat diketahui bahwa pemanfaatan processor pada server localhost yaitu $5.0 \%$ dan pemanfaatan memorinya sebesar $40.7 \%$. Sedangkan pada sistem cloud pemanfaatan processor yang digunakan sebesar $0.5 \%$ dan pemanfaatan memorinya sebesar $85.0 \%$.

Dari hasil pengujian penggunaan CPU dan memori yang dilakukan, didapatkan bahwa penggunaan CPU pada localhost terlihat lebih besar dibandingkan pada private cloud, namun penggunaan memori pada localhost terlihat lebih sedikit dibandingkan pada sistem private cloud.

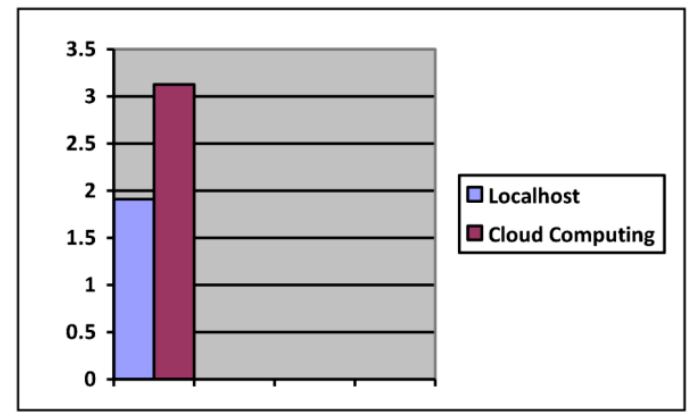

Gambar 8. Response Time (ms) Server localhost dan Sistem Cloud Computing

Hasil pengukuran waktu respon antara localhost dengan sistem cloud computing ditunjukkan pada Gambar 8. Dari hasil pengukuran tersebut didapatkan bahwa waktu respon rata-rata sistem private cloud lebih besar dari waktu respon rata-rata pada server localhost. Rata-rata waktu respon pada server localhost yaitu $1.91 \mathrm{~ms}$ sedangkan rata-rata waktu respon pada server private cloud yaitu $3.013 \mathrm{~ms}$.

Dari hasil pengujian waktu respon rata-rata yang dilakukan pada localhost dan private cloud didapatkan bahwa waktu respon rata-rata pada localhost lebih kecil atau lebih cepat dibandingkan pada private cloud dengan selisih $1.103 \mathrm{~ms}$.

\section{Kesimpulan}

Pada penelitian ini telah dilakukan perancangan dan implementasi sistem berbasis private cloud untuk kebutuhan sistem informasi akademik Politeknik Purbaya yang dibangun di atas server virtual dengan menggunakan Proxmox-VE sebagai fondasi utamanya. Private Cloud yang telah dibangun mampu menyediakan antarmuka yang efisien untuk proses kegiatan pengelolaan data akademik yang dapat diakses menggunakan Local Area Network.

\section{Referensi}

Agusti, I 2013, Rancang Bangun Pivate Cloud Computing Pada Sekretariat DPRD Provinsi SUMSEL, STMIK PalComTech, 
http://news.palcomtech.com/, viewed pada Februari 2015.

Bary, D K \& Dick, D 2013, Web Services, Service-Oriented Architectures, and Cloud Computing, $\left(2^{\text {nd }} E d\right)$, USA.

Budiyanto, A 2012, Pengantar Cloud Computing, CloudIndonesiA,http://www.cloudindonesia.or .id, viewed pada Januari 2015.

Erl, T, Zaigham, M \& Ricardo, P 2013, Cloud Computing: Concepts, Technology \& Architecture, USA, Prentice Hall.

Goldman, J E \& Rawles, P T 2004, Applied Data Communications: A Business-Oriented Approach - 4th Edition, Wiley.

Goyal, S 2014, 'Public vs Private vs Hybrid vs Community - Cloud Computing: A Critical Review', International Journal Computer Network and Information Security, vol. 3, pp. 20-29.

Hartanto K, Adian, F R \& Kodrat, I S, 2012, 'Implementasi Virtual Private Server Menggunakan Xen Hypervisor', Undergraduate Thesis, Universitas Diponegoro.

Jadeja, Y \& Modi, K, 2012, 'Cloud Computing Concepts, Architecture and Challenges', in International Conference on Computing, Electronics and Electrical Technologies [ICCEET]2012, pp. 877-880
Mell, P \& Timothy, G 2011, The NIST Definition of Cloud Computing, U.S. Department of Commerce: National Institute of Standards and Technology Special Publication 800-145.

Miller, M 2009, Cloud Computing: Web-Based Applications That Change the Way You Work and Collaborate Online, USA, Que Publishing.

Prasetyo, S Y J 2007, Desain Sistem Interkoneksi pada Arsitektur Komputasi Cluster, Salatiga, Jurnal Teknologi Informasi-Aiti, Vol. 4. No. 1.

Purbo, O W 2011, Petunjuk Praktis Cloud Computing Menggunakan Open Source, IT Camp 2011.

Silberschatz, A, Galvin, P B, \& Gagne, G 2012, Operating System Concepts, 9th Ed, Wiley.

Sosinsky, B 2011, Cloud Computing Bible. Indianapolis: Wiley Publishing, Inc.

Stiawan, D 2009, Fundamental Internerworking Develpoment \& Design Life Cycle, Universitas Sriwijaya, http://deris.unsri.ac.id/, viewed Maret 2015.

Sugianto, M V 2011, Panduan Virtualisasi \& Cloud Computing Pada Sistem Linux, Revisi 2, Bekasi.

Utomo, D P 2014, Implementasi Virtualisasi dan Server Cloud Menggunakan Proxmox VE, Politeknik Negeri Semarang. 